\title{
USINA TERMELÉTRICA A PARTIR DA CASCA DE ARROZ
}

\author{
Rafael Ludwig
}

\section{Adamo de Souza Araújo ${ }^{2}$}

\section{Fernando Ferrari Putti ${ }^{3}$}

RESUMO: A utilização de fontes de energias renováveis desempenha papel expressivo na criação de uma sociedade ecologicamente consciente, mas apenas cerca de um quinto de toda energia mundial é obtida destas, sendo $14 \%$ da biomassa e $6 \%$ da água. A Biomassa passa a ser considerada como estratégia do futuro, uma alternativa importante diante de um abastecimento energético limitado e da necessidade de uso cada vez mais racional da água. Nesse sentido, o presente trabalho é resultante de uma análise de projeto, viabilidade econômica, e dos impactos ambientais relacionados à implantação de uma Pequena Central Termelétrica junto a Cooperativa Agropecuária \& Industrial - COTRIJUI, localizada no município de Dom Pedrito/RS. Serão utilizado $43 \mathrm{t} \mathrm{dia}^{-1}$ de casca com a qual será possível produzir aproximadamente 2,28MW $\mathrm{h}$ de energia elétrica utilizando-se do turbina a vapor (ciclo Rankine). Para a implantação deste projeto será necessário um investimento inicial de $R \$ 8.726 .374,04$. Obteve-se um payback de 5 anos, o qual representa o número de períodos necessários para a recuperação do capital investido, e uma taxa interna de retorno de 24,26\%. Assim, dentro dos limites estudados e com base nos indicadores econômicos, o projeto de implantação da usina termelétrica apresenta-se economicamente viável. Além disso, essa proposta tem um caráter ambiental inegável, visto que não há a utilização de combustíveis fosseis para a produção de energia assim não adicionando $\mathrm{CO}_{2}$, apenas fazendo-o circular no ambiente. Também, possibilitará eliminar o excedente de casca, prejudiciais ao ambiente.

Palavras-chave: Energias renováveis. Resíduos agroindustriais. Biomassa.

\footnotetext{
${ }^{1}$ Engenheiro Agrícola, Doutorando em Agronomia - Irrigação e Drenagem, Faculdade de Ciências Agronômicas UNESP - Botucatu, rafaludwig@yahoo.com.br.

${ }^{2}$ Engenheiro Agrícola.

${ }^{3}$ Mestrando em Irrigação e Drenagem, UNESP/FCA - SP.
} 


\section{INTRODUÇÃO}

A biomassa é uma fonte renovável de energia, com escala suficiente para desempenhar papel expressivo no desenvolvimento de programas vitais de energias renováveis e na criação de uma sociedade ecologicamente consciente (HALL et al., 2002).

Um quinto de toda energia mundial é obtida a partir de fontes renováveis: de $13 \%$ a $14 \%$ a partir da biomassa e 6\% a partir da água. Nesse contexto, a biomassa representa cerca de 25 milhões de barris de petróleo por dia, além de ser responsável por um terço da energia consumida atualmente, nos países em desenvolvimento, variando de aproximadamente 90\% em países como Uganda, Ruanda a 45\% na Índia, 30\% na China e no Brasil e 15\% no México e África do Sul (HALL et al., 2002).

A dificuldade de quantificação do uso da biomassa energética acarreta problemas adicionais, visto que poucas vezes é incluída nas estatísticas oficiais e, quando é, tende a ser desvalorizada. A utilização da bioenergia, como, por exemplo, na forma de lenha, carvão e resíduos agrícolas, são erroneamente associados com desmatamento e desertificação. Além disso, tem-se dificuldade de quantificar e manusear a biomassa, por ser uma fonte de energia dispersa, e seu uso ineficiente resulta em pouca energia útil. Porém, este panorama está mudando, devido aos importantes esforços feitos por meio de estudos, demonstrações e plantas-piloto, a crescente utilização como um agente energético moderno e reconhecimento dos benefícios ambientais, locais e globais do uso da biomassa (HALL et al., 2002).

Para Perozzi (2004), a biomassa vegetal surge como alternativa - diante de um abastecimento energético limitado e da necessidade de uso cada vez mais racional da água, principal fonte de energia primária do país, além de sua utilização contribuir para a redução nas emissões de gases de efeito estufa.

Nesse contesto, no Rio Grande do Sul, a casca de arroz destaca-se entre os resíduos agrícolas, por ser produzido em grandes quantidades, o que favorece a sua utilização para geração de energia elétrica. Com isso, preserva-se o meio ambiente, diminui-se custos de armazenagem e transporte desse resíduo reduzindo os gastos com 
energia elétrica e ainda gera como subproduto, a sílica, que possui crescente valor de mercado (PEROZZI, 2004).

Este artigo trata de uma análise crítica da viabilidade econômica e dos impactos ambientais das atividades envolvidas para implantação de uma Pequena Central Termelétrica, a partir da queima da casca de arroz na Cooperativa Agropecuária \& Industrial - COTRIJUI, localizada no município de Dom Pedrito/RS. Este projeto foi pensado no intuito de buscar suprir a necessidade de energia elétrica da cooperativa, com possível venda do excedente da energia gerada.

\section{REVISÃO BIBLIOGRÁFICA}

O consumo de energia é um dos principais indicadores do desenvolvimento econômico e do nível de qualidade de vida de qualquer sociedade. Ele reflete tanto o ritmo de atividade dos setores industrial, comercial e de serviços, quanto à capacidade da população para adquirir bens e serviços tecnologicamente mais avançados, como automóveis (que demandam combustíveis), eletrodomésticos e eletroeletrônicos (que exigem acesso à rede elétrica e pressionam o consumo de energia elétrica) (ANEEL, 2008).

Observa-se na Figura 1, que de 2001 a 2007 a economia mundial viveu um ciclo de vigorosa expansão, refletida pela variação crescente do PIB: 3,6\% em 2003; 4,9\% em 2004; 4,4\% em 2005; 5\% em 2006 e 4,9\% em 2007. No mesmo período, a variação acumulada do consumo de energia foi de 13\%, passando de 9 milhões de toneladas equivalentes de petróleo (tep) em 2003 para 11 milhões de tep em 2007 (ANEEL, 2008).

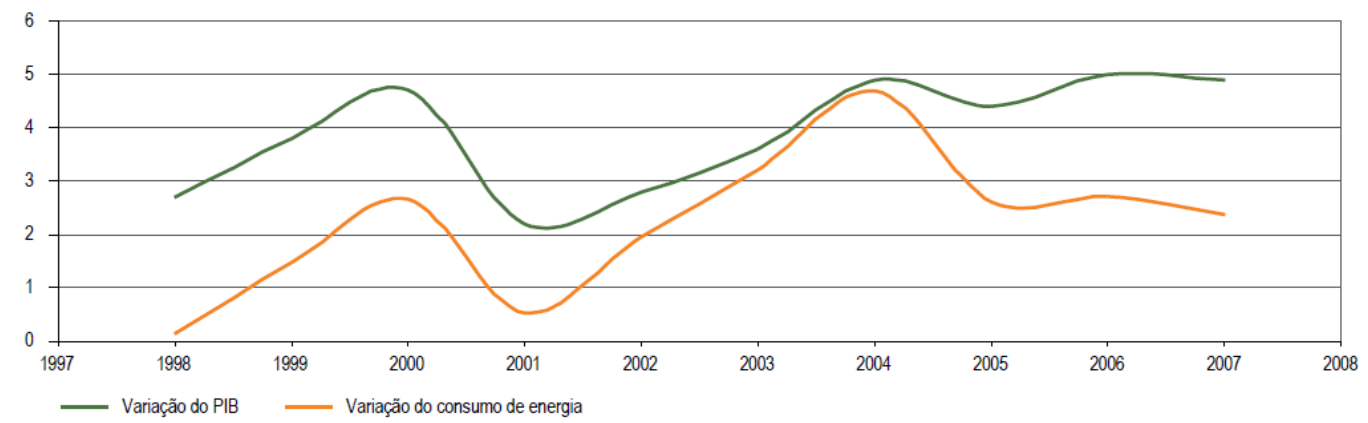

Figura 1 - Variação do PIB e variação do consumo de energia (1998 - 2007).

FONTE: BP, 2008 apud ANEEL, 2008. 
No Brasil o consumo total de energia elétrica passou de 18TW h em 1960 para 304 TW h em 2000, o que representa uma taxa de crescimento média anual no período de $7,35 \%$. Na década de 60 , o crescimento no consumo residencial foi de $8,22 \%$, o comercial de $7,81 \%$ e o industrial de $7,06 \%$. Já na década de 70 , o setor industrial teve maior expansão no consumo de energia, com um crescimento médio anual de 13,62\% (SCHMIDT et al., 2003).

Na Figura 2 observa-se o consumo de energia elétrica per capita no ano de 2007, em toneladas equivalentes de petróleo. Nota-se que o Brasil está entre os menores consumidores mundiais ( 0 a 1,5 tep). Os 30 países desenvolvidos que compõem a Organização para Cooperação e Desenvolvimento Econômico $(\mathrm{OCDE})^{4}$ são, historicamente, os maiores consumidores mundiais de energia (ANEEL, 2008).

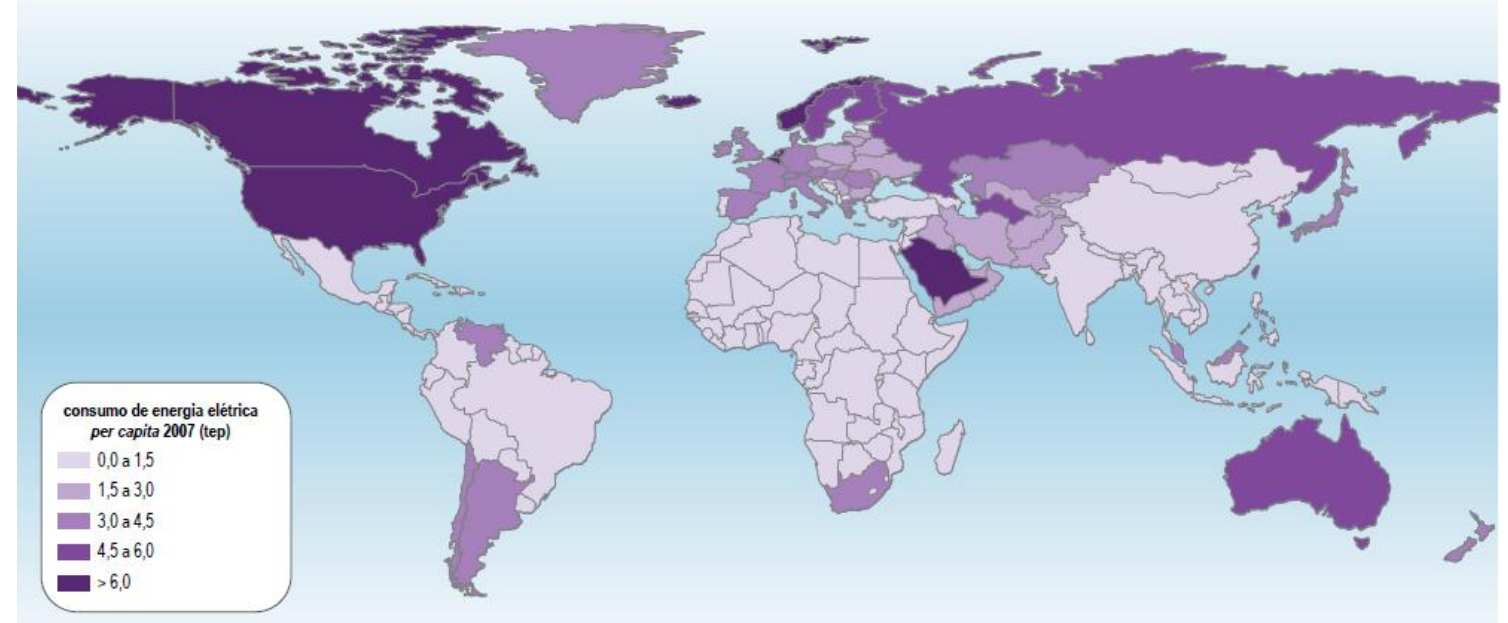

Figura 2 - Consumo de energia elétrica per capita em 2007, em toneladas equivalentes de petróleo (tep).

FONTE: BP, 2008 apud ANEEL, 2008.

No Brasil, a geração de energia elétrica provém essencialmente de duas fontes energéticas: hidráulica e do petróleo, com grande predominância da primeira (ANEEL, 2002). Segundo Mattos (2005), aproximadamente $90 \%$ da capacidade de geração de

\footnotetext{
${ }^{4}$ Os países da OCDE relacionados pela IEA são: Austrália, Áustria, Bélgica, Canadá, República Tcheca, Dinamarca, Finlândia, França, Alemanha, Grécia, Hungria, Islândia, Irlanda, Itália, Japão, Coréia, Luxemburgo, México, Países Baixos, Nova Zelândia, Noruega, Polônia, Portugal, República Eslovaca, Espanha, Suécia, Suíça, Turquia, Reino Unido e Estados Unidos.
} 
energia elétrica instalada é de origem hidráulica, isso se deve em grande parte às condições geográficas favoráveis.

Destaca-se que a busca por alternativas energéticas deve ser uma constante, apontando-se os resíduos agroindustriais como uma possibilidade, com grande destaque para arroz que é um dos alimentos mais antigos produzidos pelo homem, com registros de 3000 a.C., que mencionavam a cerimônia de semeadura do arroz na China. Cultivado em todos os continentes, é a terceira cultura agrícola em importância mundial, perdendo apenas em produção para o milho e o trigo, porém, esses grãos são largamente utilizados para outros fins além da nutrição humana (SILVA, 2004).

Depois de colhido, o arroz passa por processos de beneficiamento, entre eles, o descascamento, no qual a casca, que totaliza $20 \%$ do peso total, é separada do grão (DINIZ, 2005). O mesmo autor destaca a problemática do descarte da casca, devido as suas propriedades - de difícil decomposição e também pela enorme quantidade gerada anualmente. Corroborando, Mayer et al. (2007) informam que muitos produtores de arroz utilizam de forma indireta a compostagem da casca, com o objetivo de reduzir a sua carga orgânica. Apontam ainda, como problema deste tratamento, o tempo que a casca do arroz leva para se decompor, aproximadamente 5 anos.

Anualmente são produzidos no Brasil aproximadamente 13 milhões de toneladas de casca de arroz, sendo o Rio Grande do Sul responsável por 46\% do total (MAYER et al., 2006). Esse resíduo é considerado de classe II, segundo a Norma brasileira de classificação de resíduos sólidos, ou seja, não inerte e não perigoso à saúde humana e ao meio ambiente (ABNT, 2004).

A casca de arroz é disponibilizada durante o ano todo, e com fornecimento constante, devido ao fato do arroz em casca ser a melhor maneira de armazenar o produto. Esse fator é favorável a sua utilização para fins energéticos (AMATO, 2002).

Com poder calorífico de $3200 \mathrm{kcal} \mathrm{kg}^{-1}$, a utilização da casca de arroz, para geração de energia elétrica, além de proporcionar melhorias ao meio ambiente, pode agregar valor ao arroz produzido pelas indústrias. Além disso, a casca apresenta baixa densidade, em torno de $130 \mathrm{~kg} \mathrm{~m}^{-3}$, resultando num grande volume necessário para o seu armazenamento (MAYER et al., 2006). 
Como resíduo oriundo da queima da casca do arroz tem-se a cinza, a qual representa aproximadamente $16 \%$ do peso da casca. Com formas estruturais variáveis (amorfa e/ou cristalina), que dependem tanto do tipo de equipamento utilizado (processo artesanal a céu aberto, grelhas, processo industrializado por leito fluidizado com ou sem controle da temperatura), como do tempo e temperatura de queima. A casca de arroz queimada em condições controladas (temperatura máxima de $1000^{\circ} \mathrm{C}$ ), ao atingir $800^{\circ} \mathrm{C}$, gera cinza residual constituída de sílica em forma cristalina de quartzo. Para temperaturas no intervalo de 450 a $700^{\circ} \mathrm{C}$, gera sílica no estado amorfo (FERRO et al., 2007).

Alguns engenhos possuem geração de energia elétrica com tecnologia do início do século XX (motor síncrono de pistão recíproco ou locomóvel), porém, as mais recentes utilizam turbina a vapor (ciclo Rankine), com potência superior a 2MW, sendo comprovadamente viáveis economicamente. Para potências inferiores, a viabilidade da instalação deve ser avaliada (MAYER et al., 2007).

Lopes (2007) descreveu o ciclo Rankine como o aproveitamento da energia de combustão a qual gera vapor que alimenta uma turbina onde o vapor é expandido gerando energia mecânica, que é convertida em energia elétrica através de um gerador. O ciclo é completado pela condensação do vapor exausto da turbina e posterior bombeamento e pré-aquecimento até a condição de entrada na caldeira novamente. O ciclo Rankine é o ciclo da água/vapor que compreende idealmente os seguintes processos:

$>$ 1-2: Aumento de pressão (bombeamento) adiabático da água;

> 2-3: Fornecimento de calor a pressão constante levando à evaporação da água e subsequente superaquecimento do vapor;

> 3-4: Expansão adiabática do vapor na turbina;

> 4-1: Condensação do vapor à pressão constante.

Segue, na Figura 3, um esquema com os principais equipamentos e processos do ciclo Rankine convencional. O diagrama T-S apresentado na Figura 4 representa o ciclo Rankine ideal: 


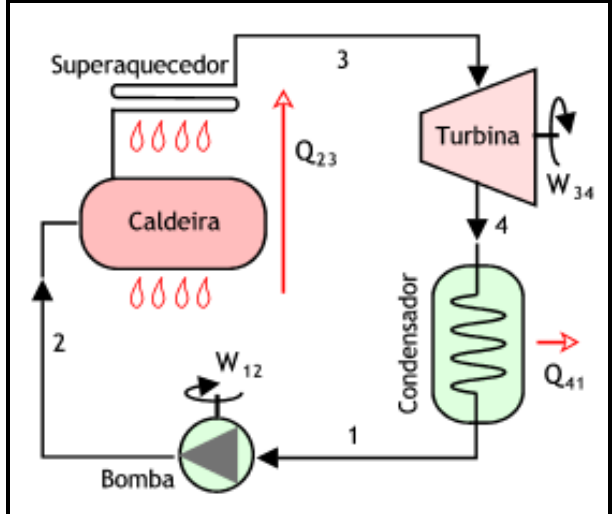

Figura 3 - Esquema Simplificado do Ciclo Rankine

FONTE: Lopes, 2007

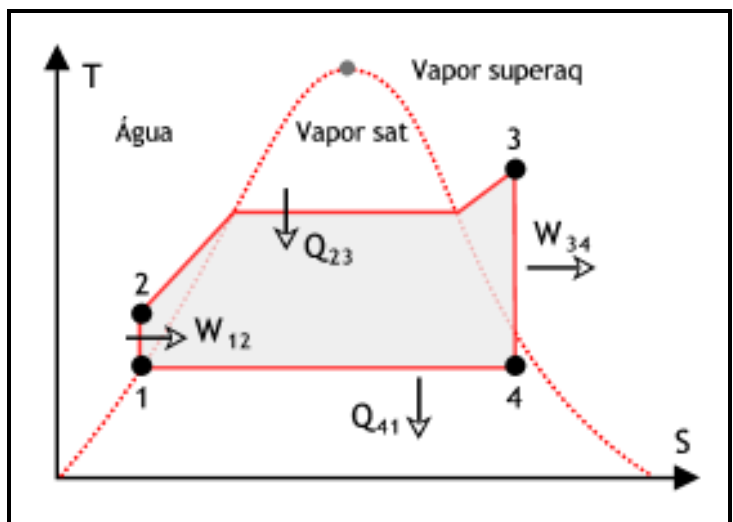

Figura 4 - Diagrama T-S do ciclo Rankine ideal com superaquecimento FONTE: Lopes, 2007

No ciclo Rankine real existem perdas por atrito e por condução e radiação de calor o que reduz a eficiência do ciclo, a qual pode ser ampliada com a utilização das seguintes alterações:

$>$ Reaquecimento: o vapor é expandido em um primeiro conjunto de estágios de turbina (sessão de alta pressão) até uma pressão intermediária e passa por um reaquecedor na caldeira antes de ser admitido pelo segundo conjunto de estágios da turbina (sessão de baixa pressão). Esta alternativa tem a vantagem de aumentar a potência gerada aumentando a área que representa o trabalho realizado no diagrama T-S sem exceder as limitações metalúrgicas (El Wakil, 1984 apud Lopes, 2007);

Nas Figura 5 e Figura 6, apresenta-se o esquema operando com reaquecimento e o respectivo diagrama T-S para o ciclo ideal.

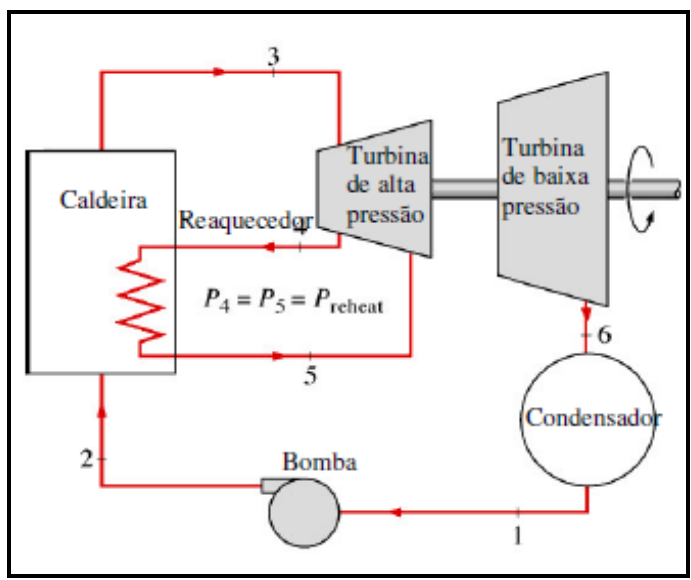

Figura 5 - Esquema de um ciclo Rankine com reaquecimento

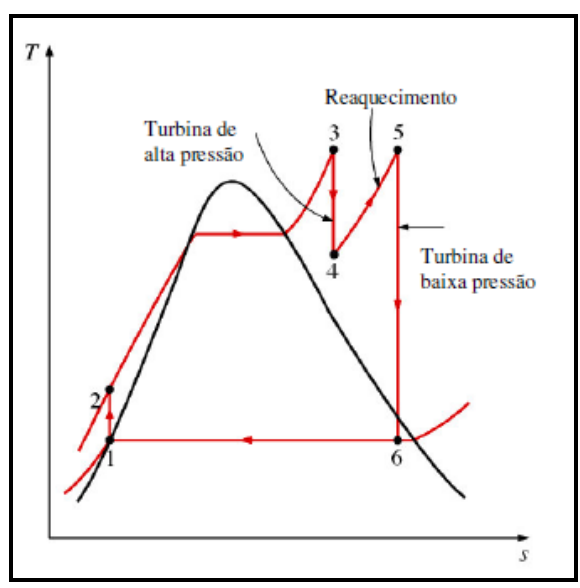

Figura 6 - Diagrama T-S do ciclo

Rankine ideal com reaquecimento 
FONTE: adaptado de Lopes, 2007.

FONTE: adaptado de Lopes, 2007.

$>$ Regeneração: consiste na troca de calor entre extrações de vapor da turbina e a água de alimentação de caldeira. Esta alternativa permite um aumento na temperatura média do fluido de trabalho o que aumenta a eficiência termodinâmica do ciclo.

Nas Figura 7 e Figura 8 é mostrado o esquema de uma planta operando com regeneração e o respectivo diagrama T-S para o ciclo ideal.

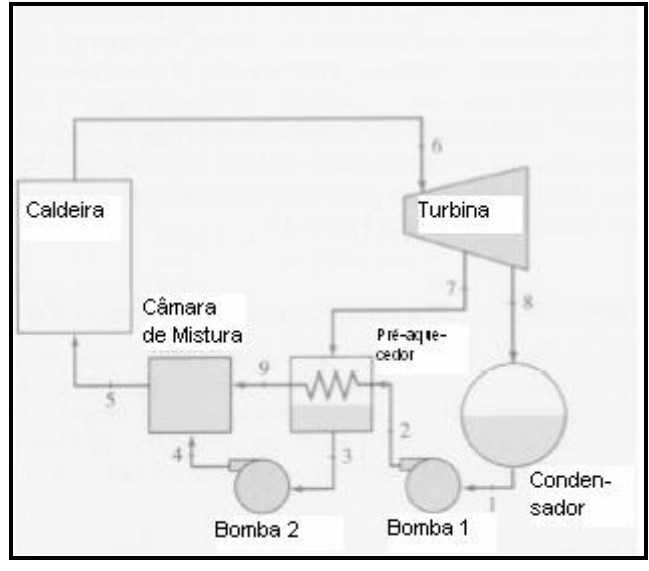

Figura 7 - Esquema do ciclo Rankine com regeneração

FONTE: Lopes, 2007

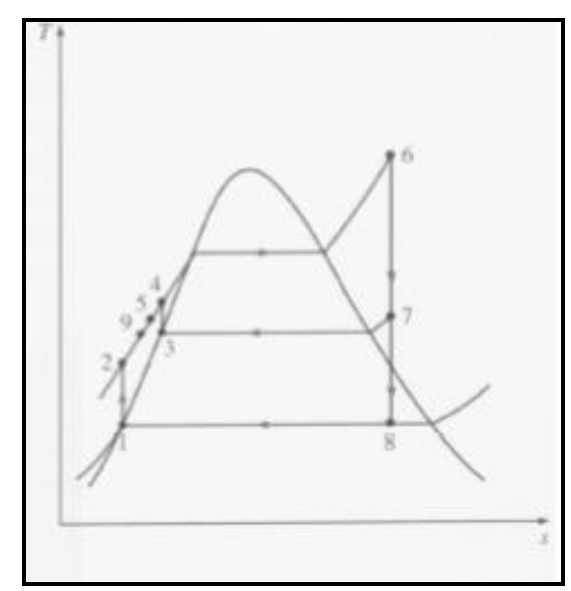

Figura 8 - Diagrama T-S do ciclo Rankine ideal com regeneração FONTE: Lopes, 2007

\section{MATERIAL E MÉTODOS}

Este estudo foi realizado em parceria com a Cooperativa Agropecuária \& Industrial COTRIJUI, localizada na BR 293, km 237 - Dom Pedrito / RS.

Para avaliar a possibilidade de instalação da usina termelétrica associada à indústria de beneficiamento de arroz levantou-se a produção de casca diária e estimou-se quanto poderia ser destinado à geração termelétrica. Para isso, descontou-se o que é utilizado nos processos de secagem e parboilização do arroz e avaliou-se a quantidade de energia elétrica que seria possível produzir, levando em consideração o poder calorífico da casca, a eficiência dos equipamentos, e a probabilidade de venda de possíveis excedentes de energia.

Para a transformação energética selecionou-se o sistema do tipo Rankine, o mesmo utilizado na geração térmica convencional com combustíveis fósseis, e pode ser resumido 
da seguinte forma: queima ou combustão do resíduo, geração de vapor, geração de trabalho na turbina pelo vapor e geração de eletricidade.

Tendo isso em mente, calculou-se a Energia produzida pelo gerador as equações de 1 a 4:

$Q_{\text {CTE }}=\operatorname{Pc} C 4,84 \times 10^{-05}$

Em que:

$\mathrm{Q}_{\mathrm{CTE}}$ : Consumo total de calor na central termelétrica ( $\mathrm{MW} \mathrm{h}$ );

Pc: Poder calorífico (kcal kg ${ }^{-1}$ );

C: Queima de combustível (t dia $\left.{ }^{-1}\right)$;

$Q_{\text {cald }}=Q_{\text {CTE }} \eta_{\text {cald }}$.

Em que:

$Q_{\text {cald: }}$ energia do vapor que sai do gerador (MW h);

$\eta_{\text {cald }}:$ Rendimento da caldeira;

$Q_{\text {turb }}=Q_{\text {cald }} \eta_{\text {turb }}$

Em que:

$Q_{\text {turb }}$ : corresponde ao calor que chega ao gerador $\left(\mathrm{MW} \mathrm{h}^{-1}\right)$;

$\eta_{\text {tub }}$ : corresponde ao rendimento da tubulação, obtido de LORA, et AL. (2004). $W_{\text {elet }}=\eta_{\text {ger }} x Q_{\text {turb }}$

Em que:

$\mathrm{W}_{\text {elt: }}$ : Energia produzida pelo gerador (MW)

$\eta_{\text {ger }}$ : corresponde ao rendimento do gerador, obtido de LORA, et AL. (2004).

Assim, construiu-se um projeto para implantação dessa termelétrica e a partir dele estimou-se o custo-benefício da implantação dessa estrutura, e realizaram-se considerações a respeito desse processo.

\section{RESULTADOS E DISCUSSÃO}

O projeto considerou que na indústria em questão o processo de beneficiamento do arroz produz $18000 \mathrm{t} \mathrm{ano}^{-1}$ de casca, sendo que, durante 4 meses são utilizados $40 \%$ da produção diária de casca na secagem do arroz, o que totaliza $2400 \mathrm{t} \mathrm{ano}^{-1}$. Isso dá um 
excedente anual de $15600 \mathrm{t} \mathrm{ano}^{-1}$, o que da uma media diária de $43 \mathrm{t}$, a qual será utilizado para produção de energia. Então se estimou a geração de energia elétrica a partir da casca de arroz e o balanço de massa do processo como pode ser observado no fluxograma que segue (Figura 9).

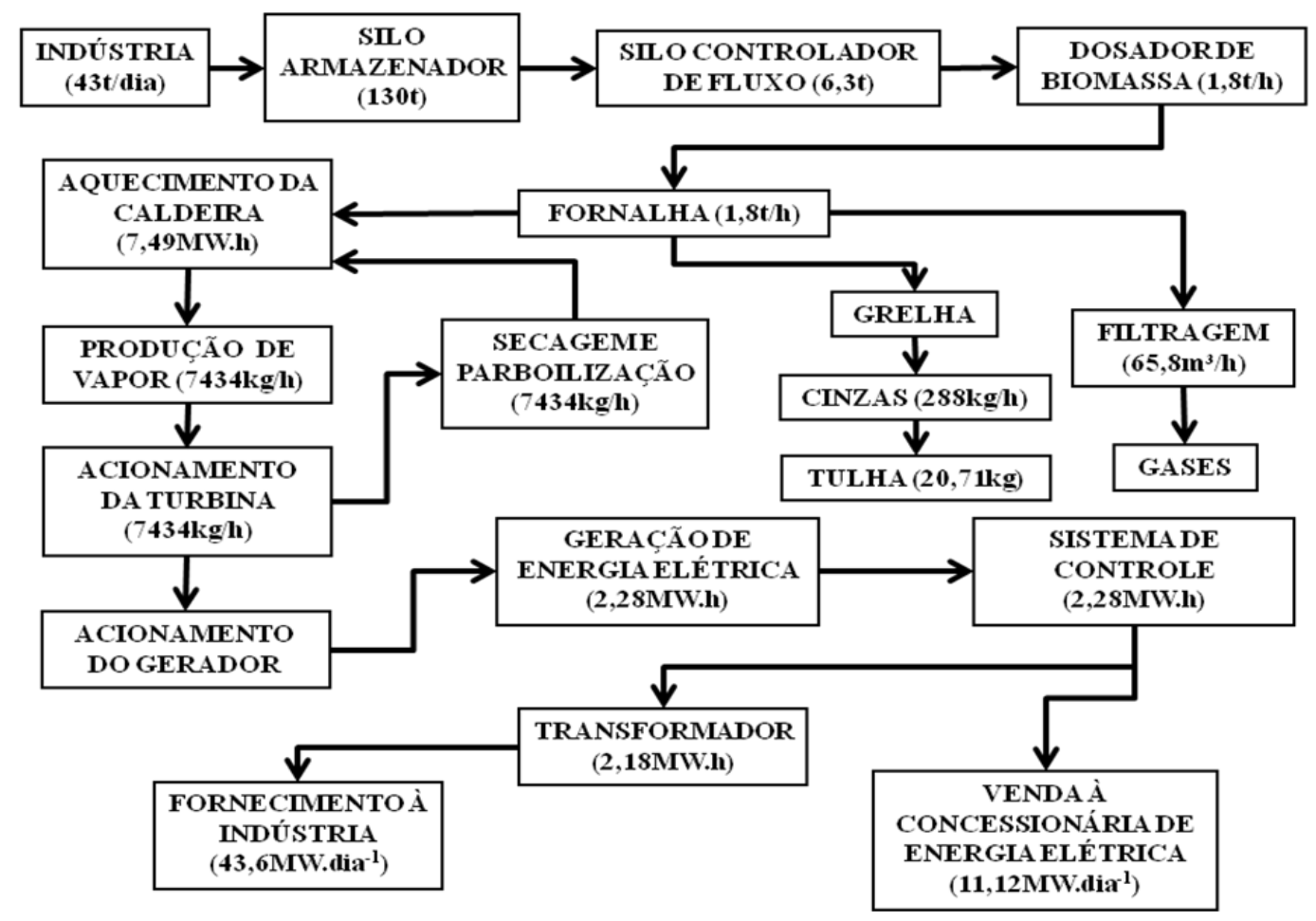

Figura 9 - Fluxograma e balanço de massa do projeto da termelétrica a partir da casca de arroz

Entende-se a partir disso, que o arroz chega à indústria onde separa-se o grão da casca, a qual corresponde a $20 \%$ do peso do arroz beneficiado. Após isso a casca é depositada em uma moega, onde é transportada por um elevador de canecas até o nível superior do silo e por gravidade será depositado no silo armazenador. Este terá capacidade de estocagem de material necessário para 3 dias de trabalho da termelétrica, aproximadamente 130 t. O volume total armazenado será de 1130,00 $\mathrm{m}^{3}$.

Do silo armazenador, a casca será transportada e depositada em um silo controlador de fluxo, o qual terá capacidade de armazenagem de 6,3 t correspondendo a 3,5 horas de funcionamento do sistema. Após a casca será destinada para o dosador de biomassa, na entrada da caldeira, alimentando o sistema de queima. 
A queima da casca será feita na fornalha, dentro da caldeira, com alimentação constante de $1,8 \mathrm{t} \mathrm{h}^{-1}$, no entanto devido às características do equipamento pode-se queimar até 2,37 $\mathrm{t} \mathrm{h}^{-1}$ de casca, acima desse valor há necessidade de mudar os equipamentos. Este processo terá com um dos subprodutos a cinza. Grande parte desta será levada até a tulha, com capacidade de armazenar 21 t de cinza o que corresponde aproximadamente a 3 dias de funcionamento da termelétrica. Outra parte estará suspensa junto com os gases de combustão, os quais passarão por dois multiciclones que atuarão no resfriamento dos gases e da cinza, e na retirada algumas partículas, o restante será removido por um filtro manga.

Estima-se que com a queima de 1,8 $\mathrm{t} \mathrm{h}^{-1}$ de casca de arroz, com poder calorífico de $3600 \mathrm{kcal} \mathrm{kg}^{-1}$, produzir-se-ão 7,49 MW h. Com isto, será possível aquecer a caldeira e consequentemente produzir $7434 \mathrm{~kg}$ de vapor com temperatura de $450^{\circ} \mathrm{C}$ e pressão de 45 $\mathrm{kgf} \mathrm{m}^{-2}$. Através de uma tubulação esse vapor superaquecido será levado até a turbina, transforma a energia de pressão em energia mecânica, que faz girar um eixo ligado em um gerador. $O$ vapor sairá da turbina com pressão de $12 \mathrm{kgf} \mathrm{cm}^{-2}$ e praticamente a mesma temperatura, e através da tubulação passará para a indústria para aproveitar-se a sua pressão e calor nos processos de secagem e parboilização. Após, retornará a caldeira, onde o ciclo será repetido.

O gerador terá uma potência de 3000 kVA e uma tensão de saída 13800 V. A saída do gerador está ligada nos sistemas de controle onde será feito monitoramento e controle da tensão gerada. Parte da energia estará ligada na rede de distribuição da concessionária e a outra parte em um transformador, com uma potência de 3000 kVA e saída de tensão de 380/220 V, para alimentar a unidade beneficiadora de grão e a usina termelétrica.

Para funcionamento da termelétrica, serão necessários 10 funcionários, sendo 6 técnicos eletromecânicos, os quais terão turnos de trabalho de 6 horas, totalizando 27 horas por semana, um engenheiro que será responsável pela administração, um funcionário para serviços gerais e 2 motoristas, que serão responsáveis pelo transporte da cinza.

Deste modo, elaborou-se o fluxo de caixa considerando 10 anos de funcionamento da termelétrica conforme Tabela 1. 


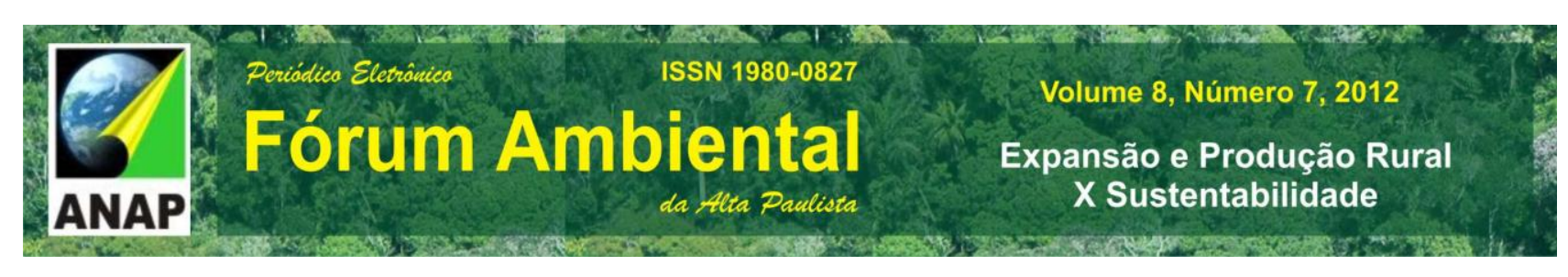

Tabela 1 - Fluxo Caixa

\begin{tabular}{|c|c|c|c|c|c|c|c|c|c|c|c|}
\hline Descrição & $\mathbf{0}$ & 1 & 2 & 3 & 4 & 5 & 6 & 7 & 8 & 9 & 10 \\
\hline Receita Bruta & & 3.588.987,09 & 3.588.987,09 & 3.588.987,09 & 3.588.987,09 & 3.588.987,09 & 3.588.987,09 & 3.588.987,09 & 3.588.987,09 & 3.588.987,09 & 3.588.987,09 \\
\hline \multicolumn{12}{|l|}{ (-) Impostos Prop. } \\
\hline ICMS & & $179.620,80$ & $179.620,80$ & $179.620,80$ & $179.620,80$ & $179.620,80$ & $179.620,80$ & $179.620,80$ & $179.620,80$ & $179.620,80$ & $179.620,80$ \\
\hline PIS/COFINS & & $124.441,87$ & $124.441,87$ & $124.441,87$ & $124.441,87$ & $124.441,87$ & $124.441,87$ & $124.441,87$ & $124.441,87$ & $124.441,87$ & $124.441,87$ \\
\hline Receita Líquida & & 3.284.924,42 & $3.284 .924,42$ & 3.284.924,42 & 3.284.924,42 & 3.284.924,42 & 3.284.924,42 & $3.284 .924,42$ & 3.284.924,42 & $3.284 .924,42$ & 3.284.924,42 \\
\hline Custo Var. Prod. & & $363.682,97$ & $363.682,97$ & $363.682,97$ & $363.682,97$ & $363.682,97$ & $363.682,97$ & $363.682,97$ & $363.682,97$ & $363.682,97$ & $363.682,97$ \\
\hline Custo Fixo Prod. & & $532.233,20$ & $532.233,20$ & $532.233,20$ & $532.233,20$ & $532.233,20$ & $532.233,20$ & $532.233,20$ & $532.233,20$ & $532.233,20$ & $532.233,20$ \\
\hline Lucro Bruto & & $2.389 .008,25$ & $2.389 .008,25$ & $2.389 .008,25$ & $2.389 .008,25$ & $2.389 .008,25$ & $2.389 .008,25$ & $2.389 .008,25$ & $2.389 .008,25$ & $2.389 .008,25$ & $2.389 .008,25$ \\
\hline Desp. Ger. Var. & & 0,00 & 0,00 & 0,00 & 0,00 & 0,00 & 0,00 & 0,00 & 0,00 & 0,00 & 0,00 \\
\hline Desp. Ger. Fixas & & $60.336,47$ & $60.336,47$ & $60.336,47$ & $60.336,47$ & $60.336,47$ & $60.336,47$ & $60.336,47$ & $60.336,47$ & $60.336,47$ & $60.336,47$ \\
\hline Depreciação & & $726.366,30$ & $726.366,30$ & $726.366,30$ & $726.366,30$ & $726.366,30$ & $726.366,30$ & $726.366,30$ & $726.366,30$ & $726.366,30$ & $726.366,30$ \\
\hline Despesas Finan. & & $418.900,30$ & $418.900,30$ & $314.175,22$ & $209.450,15$ & $104.725,07$ & 0,00 & 0,00 & 0,00 & 0,00 & 0,00 \\
\hline Valor Contabil & & 0,00 & 0,00 & 0,00 & 0,00 & 0,00 & 0,00 & 0,00 & 0,00 & 0,00 & $-249.032,52$ \\
\hline Lucro Antes IR & & $1.183 .405,19$ & 1.183.405,19 & $1.288 .130,26$ & $1.392 .855,34$ & $1.497 .580,41$ & $1.602 .305,48$ & $1.602 .305,48$ & $1.602 .305,48$ & $1.602 .305,48$ & $1.602 .305,48$ \\
\hline IR/Contrib. Social & & $378.357,76$ & $378.357,76$ & $413.964,29$ & $449.570,81$ & $485.177,34$ & $520.783,86$ & $520.783,86$ & $520.783,86$ & $520.783,86$ & $520.783,86$ \\
\hline Lucro Líq. Após IR & & $805.047,42$ & $805.047,42$ & 874.165,97 & 943.284,52 & $1.012 .403,07$ & $1.081 .521,62$ & $1.081 .521,62$ & $1.081 .521,62$ & $1.081 .521,62$ & $1.081 .521,62$ \\
\hline (+) Depreciação & & $726.366,30$ & $726.366,30$ & $726.366,30$ & $726.366,30$ & $726.366,30$ & $726.366,30$ & $726.366,30$ & $726.366,30$ & $726.366,30$ & $726.366,30$ \\
\hline (-) Amortização & & 0,00 & $1.309 .063,43$ & $1.309 .063,43$ & $1.309 .063,43$ & $1.309 .063,43$ & 0,00 & 0,00 & 0,00 & 0,00 & 0,00 \\
\hline (-) Investimentos & $8.727 .089,53$ & 0,00 & 0,00 & 0,00 & 0,00 & 0,00 & 0,00 & 0,00 & 0,00 & 0,00 & 0,00 \\
\hline (+)Liber. Financiam. & $5.236 .253,72$ & 0,00 & 0,00 & 0,00 & 0,00 & 0,00 & 0,00 & 0,00 & 0,00 & 0,00 & 0,00 \\
\hline (+) Valor Residual & & 0,00 & 0,00 & 0,00 & 0,00 & 0,00 & 0,00 & 0,00 & 0,00 & 0,00 & $1.214 .393,99$ \\
\hline Fluxo de Caixa Empr & $-3.490 .835,81$ & $1.531 .413,72$ & $222.350,30$ & 291.468,84 & $360.587,39$ & 429.705,94 & $1.807 .887,92$ & $1.807 .887,92$ & 1.807.887,92 & 1.807.887,92 & 1.807.887,92 \\
\hline
\end{tabular}

VIII Fórum Ambiental da Alta Paulista, v. 8, n. 7, 2012, p. 79-93. 
Assim, o investimento inicial para instalação de termelétrica fica em torno de $R \$$ 8.696.620,85, compreendendo instalações, terreno, equipamentos, licenças, etc. Considerando os indicadores econômicos, obteve-se um payback, o qual representa 0 número de períodos necessários para a recuperação do capital investido de 5 anos.

O projeto apresentou uma TIR de 24,26\%. O valor presente líquido (VPL), método que consiste em transferir para o presente (ano zero) todos os saldos de caixa ao longo do horizonte de planejamento ficou em $\mathrm{R} \$ 6.829 .928,84$.

\section{CONCLUSÃo}

Com a implantação deste sistema de geração de energia elétrica eliminar-se-á o acúmulo de casca, prejudiciais ao ambiente, assim como a cinza para a qual será dado um destino adequado, fechando com isso, a cadeia produtiva do arroz. Além disso, o processo não utiliza combustíveis fósseis para a produção de energia, não adicionando $\mathrm{CO}_{2}$, apenas fazendo-o circular no ambiente, o que dá um caráter ambiental importante ao projeto.

Considerando que sejam feitos os investimentos propostos no projeto e com base nos indicadores econômicos (payback, VPL e TIR), o projeto de implantação da usina termelétrica a casca de arroz apresenta-se economicamente viável.

\section{REFERÊNCIAS}

AMATO, Gilberto Wageck. Casca: agregando valor ao arroz. Disponível em: <http://www.irga.rs.gov.br/arquivos/20050815133443.pdf>. Acesso em: 15 de out. 2009.

ANEEL - Agência Nacional de Energia Elétrica (Brasil). Atlas de energia elétrica do Brasil. 3.ed. Brasília: Aneel, 2008. 236p.

ANEEL - Agência Nacional de Energia Elétrica (Brasil). Panorama do potencial de biomassa no Brasil. 2.ed. 2002. Disponível em:

<http://www.aneel.gov.br/biblioteca/downloads/livros/panorama_biomassa.pdf>. Acessado em: out. 2009. 
ASSOCIAÇÃO BRASILEIRA DE NORMAS TÉCNICAS. NBR 10004. Resíduos Sólidos Classificação. Rio de Janeiro, 2004. 71p. Disponível em:

<http://www.aslaa.com.br/legislacoes/NBR\%20n\%2010004-2004.pdf>. Acesso em: 10 de out. 2009.

DINIZ, Juraci. Conversão térmica de casca de arroz à baixa temperatura: produção de bioóleo e resíduo sílico-carbonoso adsorvente. 2005. 156f. Tese (Doutorado em Química)Centro de Ciências Naturais e Exatas, Universidade Federal de Santa Maria, Santa Maria.

HALL, D. O.; HOUSE, J. I. e SCRASE, I. Overview of biomass energy. In: Industrial uses of biomass energy: the example of Brazil. London and New York. 2002. p.1-27. Disponível em: <http://www.scribd.com/doc/12608829/Industrial-Uses-of-Biomass-EnergyThe-Example-of-Brazil>. Acesso em: 11 de out. 2009.

LOPES, Carlos Thomaz Guimarães. Análise termodinâmica comparativa entre um ciclo rankine tradicional e um inovador utilizando gases residuais do processo siderúrgico como combustível. 2007. 122f. Dissertação (Mestrado em Engenharia Mecânica). Engenharia Mecânica, Pontifícia Universidade Católica do Rio de Janeiro, Rio de Janeiro.

LORA, Lecto Eduardo Silva; ARIETA, Felipe Raul Ponce; BERSSA, Fernando Calife; et al. Caldeiras de vapor convencionais e de recuperação. In: Geração termelétrica: planejamento, projeto e operação. São Paulo: Interciência, 2004. p.171-257.

MATTOS, L. B. de. Uma estimativa da demanda industrial de energia elétrica no Brasil: 1974-2002. Organ. Rurais Agroind., Lavras, v.7, n2, p. 238-246. 2005.

MAYER, Flávio Dias; CREMONESE, Guilherme; HOFFMANN, Ronaldo; et al. Análise de viabilidade econômica para uma micro central termoelétrica (mct) com biomassa residual em uma indústria de arroz. 2007. Disponível em:

<http://www.agq.com.br/congresso2007/trabalhos/Analise_de_viabilidade_\%20economica \%20para_\%20uma_\%20micro_\%20Central_Termoeletrica(MCT)_\%20comBiomassa_\% 20Residual_\%20em_\%20uma_\%20industria_\%20de_\%20arroz.pdf $>$. Acesso em: $15 \mathrm{de}$ out. 2009.

MAYER, Flávio Dias; HOFFMANN, Ronaldo; RUPPENTHAL, Janis E. Gestão energética, econômica e ambiental do resíduo casca de arroz em pequenas e médias agroindústrias de arroz. 2006. Disponível em:

<http://www.simpep.feb.unesp.br/anais/anais_13/artigos/124.pdf>. Acesso em: 15 de out. 2009.

PEROZZI, Mariana. Arroz em Foco. 2004. Disponível em: <http://www.arroz.agr.br/site/arrozemfoco/040305.php>. Acessado em: out. 2009.

SCHMIDT, Cristiane Alkmin Junqueira; LIMA, Marcos A. M. A demanda por energia elétrica no Brasil. Revista Brasileira de Economia. Rio de Janeiro, v.58, n.1, p.67-99 jan./mar. 2003. 
SILVA, Fernando Lopa. Análise competitiva do segmento de produção de arroz irrigado da cadeia agroindustrial do arroz no Rio Grande do Sul. 2004. 101f. Trabalho de conclusão de curso apresentado ao MBA em Gestão da Informação no Agronegócio da Universidade Federal de Juiz de Fora. Disponível em:

<http://www.arroz.agr.br/site/teses/zip/silva.zip>. Acesso em: 15 de out. 2009. 